\title{
Biological Variability in Clinical Isolates of Trichomonas vaginalis
}

\author{
Alicia Gómez-Barrio+ ,Juan J Nogal-Ruiz, David Montero-Pereira, \\ Ester Rodríguez-Gallego, Esperanza Romero-Fernández, José A Escario
}

\begin{abstract}
Departamento de Parasitología, Facultad de Farmacia, Universidad Complutense, Ciudad Universitaria, 28040 Madrid, España
Eighteen clinical isolates of Trichomonas vaginalis were obtained from women who attended health centers of the Goverment of Madrid. A total of 1,848 vaginal specimens recovered during the gynaecological examination were seeded in culture tubes containing liquid Diamond medium. Pathogenicity to mice was determined after intraperitoneal inoculation of mice by quantification of mortality and gross damage to abdominal organs. As could be expected, a broad variability was obtained, being some of the isolates more virulent than the reference strain. Regarding to metronidazole susceptibility, none resistant isolate was found but different degrees of susceptibility were determined.
\end{abstract}

Key words: Trichomonas vaginalis - pathogenicity to mice - metronidazole

Trichomonas vaginalis is the causative agent of the most common, non-viral sexually transmitted disease (STD). This parasite is the main cause of vaginitis, cervicitis and urethritis in women and may be responsible for prostatitis and other genito-urinary syndromes in men. Moreover, it has been related to more serious diseases as cervical neoplasia (Gram et al. 1992, Zhang \& Begg 1994, Viikki et al. 2000). An association between $T$. vaginalis infection and an increased risk of transmission of other STDs, including human immunodeficiency virus, has been also suggested (Laga et al. 1993, Sorvillo \& Kerndt 1998).

The total amount of women affected per year worldwide is around 170 millions (WHO 1997). In Spain, three studies concerning the prevalence of trichomoniasis and other STDs have been published (Perea et al. 1981, Orduña Domingo et al. 1991, Ulla et al. 1993), but in Madrid only an epidemiological survey has been recently made (Alonso Sanz et al. 1996) among the female prison population of Carabanchel.

Although the parasite does not usually cause important sequelae, there is a great variability in the pathological manifestations, from asymptomatic presentation to increased risk of pelvic inflammatory disease and tubal infertility (Cates et al. 1993). The reasons for such variation and how the characteristics of every clinical isolate impact the clinical manifestations of trichomoniasis are not well known. Despite the high prevalence and associ-

This study was supported by the Universidad Complutense, Project PR181/96.

We declare that all experiments performed comply with current Spanish laws.

${ }^{+}$Corresponding author. Fax: +34-1-394-18-15. E-mail: agbarrio@farm.ucm.es

Received 4 December 2001

Accepted 29 April 2002 ated risks of trichomoniasis, very little is also known about the biological variability of the parasite. Experimental pathogenicity is one of the parameters that can be applied to the characterization of isolates, because of it varies so broadly as clinical pathogenicity does. Regarding to treatment, during the last two decades about 20 metronidazole-resistant strains have been described from $\mathrm{Eu}$ rope (Meri et al. 2000). If, as Meri et al. (2000) suggest, the metronidazole resistance of $T$. vaginalis is an emerging threat in Europe, it is of great interest the study of the susceptibility to drug of isolates from patients.

A total of 1,848 women who were attending from June 1994 to June 1995 in 12 health centers of the Goverment of Madrid were tested for T. vaginalis. The diagnosis of trichomoniasis was based on cultivation the cervical or vaginal specimens in tubes cointaining $2 \mathrm{ml}$ of Diamond's medium (Diamond 1957). Initially, endocervical samples were taken for culture, being examined a total of 381 women with negative result for $T$. vaginalis. So, the 1,467 new samples were obtained from vaginal site.

Vaginal specimens were obtained during the gynaecological examination on cotton-tipped applicators that were immediately seeded in the culture tubes. The bottom portion of the swab was broken off into the tubes. The cultures were incubated for $24 \mathrm{~h}$ at $37^{\circ} \mathrm{C}$ and $5 \% \mathrm{CO}_{2}$ in air. Microscopic examination was made for every specimen first at $\mathrm{x} 100$ and then at $\mathrm{x} 400$ for motile trichomonads. All negative cultures were again incubated at the same conditions above mentioned and were examined at 7 days by using exactly the same procedure of the first microscopic examination.

All the isolates from positive specimens were then axenized by daily reseedings in fresh Diamond's medium containing $500 \mu \mathrm{g} / \mathrm{ml}$ streptomycin, $500 \mathrm{UI} / \mathrm{ml}$ penicillin and $100,000 \mathrm{U} / \mathrm{ml}$ nistatin and cryopreserved in liquid $\mathrm{N}_{2}$.

In order to know the pathogenicity of each isolate, batches of 10 NMRI mice, bred under standard conditions in our laboratory were used for experimental infections. Animals weighed $20-25 \mathrm{~g}$ at the beginning of the 
experiments. To inoculate the animals, $10^{7}$ trichomonads from axenic cultures were injected by the intraperitoneal route. Surviving animals were sacrified at day 15 postinfection. Both surviving animals and those that had died earlier were necropsied in order to determine the index of pathogenicity according Nogal Ruiz et al. (1997). Briefly, mortality, ascites, and the gross damage produced to the peritoneum, spleen, pancreas and stomach, and to the visceral and diaphragmatic liver faces were numerically valued to a maximum of 100 points. Stastitical differences between the pathogenicity indexes of every isolate and the reference strain were calculated by using the nonparametric Mann-Whitney U analysis.

Susceptibility to metronidazole was determined by seeding 100,000 organisms $/ \mathrm{ml}$ in glass tubes containing a final volume of $2 \mathrm{ml}$. Cultures were incubated at $37^{\circ} \mathrm{C}$ and $5 \% \mathrm{CO}_{2}$ in air. Metronidazole was dissolved in saline solution and added to the cultures $6 \mathrm{~h}$ after seeding. Twenty four hours later, viable protozoa were assessed after incubation in the presence of trypan blue using a Neubauer chamber. Three concentrations were probed, and every assayed in sextuplicate. Percentages of reduction were calculated with respect to the growth control as follows:

Percentage of reduction $=100-($ GR metronidazole $/ G R$ control) $\times 100$

being the growth rate (GR) the relation between the number of viable protozoa at $24 \mathrm{~h}$ and the number counted $6 \mathrm{~h}$ after seeding.

C1:NIH and JH 31A no. 4 T. vaginalis strains, both from American Type Culture Collection, were used as reference for pathogenicity and sensitivity to metronidazole assays, respectively.
Only 18 of 1,467 (1.2\%) women had a $T$. vaginalis infection as diagnosed by culture. If trichomoniasis serves as a marker for other STDs (Rein 1990), the low prevalence found in global population from Madrid could demonstrate how the control is improving, because of the regular access to health care. However, the size and heterogenicity of the population surveyed obligates to consider the results about prevalence with caution. Only $6(33.3 \%)$ of the women infected presented symptomatic infection, being the vaginal discharge $(22.2 \%)$ and vulvovaginal pruritus $(11.1 \%)$ the most common presenting complaints. Moreover, $50 \%$ of the women who harbored T. vaginalis revealed concomitant infection with Candida.

Two characteristics were selected to study the biological variability of the natural isolates of $T$. vaginalis: pathogenicity to mice (Table I) and susceptibility to metronidazole (Table II). Although some attempts (Bhatt et al. 1997) to correlate the clinical picture in the natural hosts and pathogenicity in mice have failed, Teras and Roigas (1966) had found that the occurence of strains with higher virulence for mice was considerably lower in patients with latent and chronic disease than in those with acute and subacute trichomoniasis. Other studies (Kulda 1990, Malyszko et al. 1991) about the correlation between relative virulence of T. vaginalis strains for murine and human hosts have been reported. According to Kulda (1990), the severity of an experimental infection with the parasite, although dependent on the responsiveness of the individual animal, reflects the inherent virulence of the inoculated strain.

As an attempt to find differences among isolates, we used a murine model standardized recently (Nogal Ruiz et

TABLE I

Pathogenicity indexes of the reference strain C1:NIH and the clinical isolates of Trichomonas vaginalis. Values are expressed as means \pm standard deviations

\begin{tabular}{lccccccc}
\hline Isolate no. & Mortality & Ascites & Peritoneum & $\begin{array}{c}\text { Spleen- } \\
\text { Pancreas- } \\
\text { Stomach }\end{array}$ & $\begin{array}{c}\text { Visceral } \\
\text { liver } \\
\text { side }\end{array}$ & $\begin{array}{c}\text { Diaphrag- } \\
\text { matic liver } \\
\text { side }\end{array}$ & $\begin{array}{c}\text { Pathogenicity } \\
\text { index }\end{array}$ \\
\hline C1:NIH & $8.7 \pm 10.3$ & $3.1 \pm 2.0$ & $8.4 \pm 1.7$ & $9.8 \pm 3.1$ & $8 \pm 2.8$ & $9.1 \pm 3.2$ & $47.1 \pm 1.5$ \\
208 & $37.4 \pm 4.4$ & $1.8 \pm 1.5$ & $10 \pm 0$ & $12 \pm 0$ & $7.8 \pm 2.0$ & $5.8 \pm 3.0$ & $74.8 \pm 5.5^{a}$ \\
1807 & $31.8 \pm 14.9$ & $2.0 \pm 1.8$ & $8.4 \pm 3.3$ & $11.2 \pm 3.8$ & $8.6 \pm 1.0$ & $7.8 \pm 1.1$ & $69.8 \pm 15^{a}$ \\
17 & $34.4 \pm 5.1$ & $1.6 \pm 1.6$ & $7.8 \pm 1.8$ & $8.8 \pm 1.0$ & $8.4 \pm 0.8$ & $7.6 \pm 2.3$ & $68.6 \pm 5.6^{a}$ \\
8232 & $12.2 \pm 12$ & $2.6 \pm 1.6$ & $9.6 \pm 1.3$ & $10.2 \pm 2.6$ & $8.4 \pm 2.6$ & $7.6 \pm 3.1$ & $50.6 \pm 12.2$ \\
3059 & $10 \pm 10.9$ & $2.2 \pm 2.7$ & $7.8 \pm 3.3$ & $10.4 \pm 2.1$ & $7.0 \pm 3.2$ & $6.6 \pm 3.1$ & $44.0 \pm 18.4$ \\
S/H & $0.6 \pm 1.9$ & $3.4 \pm 2.3$ & $8.4 \pm 1.6$ & $9.4 \pm 3.5$ & $8.4 \pm 2.5$ & $10.6 \pm 2.7$ & $40.8 \pm 9.4$ \\
3569 & $11.0 \pm 14.3$ & $2.6 \pm 2.1$ & $5.8 \pm 3.9$ & $9.0 \pm 2.7$ & $6.4 \pm 3.0$ & $5.2 \pm 3.3$ & $40.0 \pm 27.6$ \\
1540 & $4.0 \pm 7.3$ & $1.6 \pm 0.9$ & $6.4 \pm 2.3$ & $7.8 \pm 3.3$ & $6.2 \pm 4.0$ & $6.6 \pm 3.8$ & $33.6 \pm 16.1$ \\
7 & 0 & $1.6 \pm 0.9$ & $8.9 \pm 1.8$ & $10.9 \pm 3.2$ & $4.0 \pm 2.4$ & $3.1 \pm 2.9$ & $28.4 \pm 6.2^{a}$ \\
1232 & 0 & $0.2 \pm 0.6$ & $6.7 \pm 3.6$ & $7.3 \pm 2.7$ & $7.3 \pm 1.7$ & $4.0 \pm 1.6$ & $25.6 \pm 7.5^{a}$ \\
1800 & 0 & $0.8 \pm 1.0$ & $7.0 \pm 3.2$ & $7.4 \pm 4.2$ & $5.6 \pm 3.1$ & $4.4 \pm 2.6$ & $25.2 \pm 11.0^{a}$ \\
3558 & 0 & 0 & $5.8 \pm 1.3$ & $6.2 \pm 0.6$ & $2.8 \pm 1.4$ & $4.2 \pm 0.6$ & $17.6 \pm 4.6^{a}$ \\
13 & $2.6 \pm 8.2$ & 0 & $3.6 \pm 1.6$ & $5.0 \pm 1.4$ & $4.0 \pm 0$ & $2.0 \pm 0$ & $17.2 \pm 8.2^{a}$ \\
7894 & 0 & $1.2 \pm 1.0$ & $2.8 \pm 2.5$ & $5.4 \pm 3.3$ & $3.8 \pm 3.2$ & $2.6 \pm 1.9$ & $15.8 \pm 9.2^{a}$ \\
11 & 0 & 0 & $3.0 \pm 1.4$ & $7.4 \pm 0.6$ & $1.2 \pm 1.0$ & $3.0 \pm 2.2$ & $14.6 \pm 3.7^{a}$ \\
14 & 0 & 0 & $4.4 \pm 2.3$ & $5.6 \pm 1.8$ & $1.6 \pm 1.5$ & $2.0 \pm 1.3$ & $13.6 \pm 4.4^{a}$ \\
15 & 0 & 0 & $3.1 \pm 6.7$ & $5.8 \pm 1.6$ & $1.1 \pm 1.1$ & $2.0 \pm 1.7$ & $12.0 \pm 3.0^{a}$ \\
18 & 0 & 0 & $5.8 \pm 3.7$ & $4.0 \pm 3.1$ & $0.2 \pm 0.6$ & $0.4 \pm 1.3$ & $10.4 \pm 6.0^{a}$ \\
\hline
\end{tabular}

Values range: mortality (0-50), ascites (0-6), peritoneum (0-10), spleen, pancreas and stomach (0-12), visceral liver side (0-10), diaphragmatic liver side $(0-12) ; a$ : statistical significative for $\mathrm{p}<0.01$ 
TABLE II

Susceptibility to metronidazole of the reference strain JH 31A no. 4 and the clinical isolates of Trichomonas vaginalis.

Results expressed as percentages of reduction with respect to controls

\begin{tabular}{lccc}
\hline Isolate & \multicolumn{3}{c}{ Metronidazole $(\mu \mathrm{M})$} \\
\hline JH 31A & 11.5 & 6 & 3 \\
3569 & 94.9 & 92.5 & 30.2 \\
3558 & 100 & 100 & 100 \\
14 & 100 & 100 & 99.9 \\
15 & 100 & 100 & 78.9 \\
18 & 100 & 100 & 99.8 \\
3059 & 100 & 99.5 & 85.4 \\
7 & 100 & 99.1 & 85.8 \\
13 & 100 & 98.1 & 0 \\
1540 & 100 & 97.6 & 78.4 \\
S/H & 100 & 96.9 & 93.9 \\
8232 & 100 & 92.9 & 95.9 \\
7894 & 99.9 & 99.7 & 80.9 \\
1232 & 99.9 & 98.0 & 88.7 \\
11 & 99.9 & 95.7 & 70.7 \\
1800 & 99.9 & 94.4 & 88.4 \\
1807 & 99.5 & 92.9 & 61.0 \\
17 & 98.7 & 81.2 & 68.1 \\
208 & 96.5 & 93.1 & 75.3 \\
\hline
\end{tabular}

al. 1997). As could be expected, a broad variability was obtained, ranging the pathogenicity indexes from 9 to 75 . When compared to reference strain $\mathrm{C} 1: \mathrm{NIH}$, three of the new isolates, those named 208, 1807 and 17, were found to be significantly more pathogenic for mice. In a previous paper (Escario et al. 1995) the maximum value we found for pathogenicity index of five other Spanish clinical isolates was 43 , so indicating the high potential pathogenicity of the isolate 208.

Regarding to metronidazole resistance tests, all the isolates could be termed as non-resistant since values revealed slight differences among the here studied isolates. All of them showed some growth inhibition after incubation for $24 \mathrm{~h}$ with $0.5 \mu \mathrm{g}$ metronidazole $/ \mathrm{ml}(3 \mu \mathrm{M})$, which is according to Meingassner et al. (1978). Recently, Snipes et al. (2000) have performed in U.S.A. a genetic analyses on 109 clinical isolates of $T$. vaginalis. They demonstrate a high level of relatedness among isolates with in vitro metronidazole resistance. In spite of the existence of the genetic markers suggested by the authors, it must be considered that clinical isolates of $T$. vaginalis exhibit different degrees of susceptibility to metronidazole.

In our work, it is moreover noteworthy the fact that the less susceptible isolate (208) is just the most pathogenic to mice. Although new assays are need to find a possible relation between both characteristics in $T$. vaginalis, at moment this work has provide interesting biological data that can be useful to access pathogenicity assays and pharmacological screening.

\section{ACKNOWLEDGMENTS}

To all the involved health centers for providing us with the Trichomonas vaginalis isolates and Government of Madrid for technical assistance.

\section{REFERENCES}

Alonso Sanz M, Chaves F, Sánchez S, Romero N, Dronda F 1996. Microbiological study of some microorganisms implicated in sexually transmitted disease among the female prison population. Enfer Infecc Microbiol Clín 14: 474-478.

Bhatt R, Deohar L, Pandit D, Bhise R, Chateerjee DK 1997. Comparative pathogenicity of Trichomonas vaginalis isolated from symptomatic and asymptomatic cases. J Postgrad Med 43: 68-70.

Cates W, Joesoef RJ, Goldman M 1993. Atypical pelvic inflammatory disease: can we identify clinical predictors? Am J Obst Gynecol 169: 341-346.

Diamond LS 1957. The establishment of various trichomonads of animals and man in axenic cultures. J Parasitol 43: 488490.

Escario JA, Gómez Barrio A, Martínez Fernández AR 1995. The relationship of experimental pathogenicity in vivo with in vitro cytoadherence and cytotoxicity of 6 different isolates of Trichomonas vaginalis. Int J Parasitol 25: 9991000.

Gram IT, Macaluso M, Churchill J, Stalsberg H 1992. Trichomonas vaginalis (TV) and human papillomavirus (HPV) infection and the incidence of cervical intraepithelial neoplasia (CIN) grade III. Cancer Causes and Control 3: 231236.

Kulda J 1990. Employment of experimental animals in studies of Trichomonas vaginalis infection. In BM Honigberg, Trichomonads Parasitics in Humans, Springer Verlag, New York, p. 112-154.

Laga M, Manoka A, Kivuvu M, Malele B, Tuliza M, Nzila N, Goeman J, Behets F, Batter V, Alary M, Heyward WL, Ryder RW, Piot P 1993. Non-ulcerative sexually transmitted diseases as risk factors for HIV-1 transmission in women: results from a cohort study. AIDS 7: 95-102.

Malyszko E, Januszko T, Smorczewska-Czuprynska B, Ustymowicz-Farbiszewska J 1991. Virulence of Trichomonas vaginalis strains in relation to clinical forms of Trichomonas vaginitis. Wiad Parazytol 37: 219-223.

Meingassner JG, Havelec L, Mieth H 1978. Studies on strain sensitivity of Trichomonas vaginalis to metronidazole. British J Vener Dis 54: 72-76.

Meri T, Sakari Jokiranta T, Suhonen L, Meri S 2000. Resistance of Trichomonas vaginalis to metronidazole: report of the first three cases from Finland and optimization of in vitro susceptibility testing under various oxygen concentrations. J Clin Microbiol 38: 763-767.

Nogal Ruiz JJ, Escario JA, Martínez Díaz RA, Gómez Barrio A 1997. Evaluation of a murine model of experimental trichomoniasis. Parasite 2: 127-132.

Orduña Domingo A, Chu JJ, Eiros-Bouza JM, Brator-Pérez MA, Gutiérrez-Rodríguez MP, Almezar Gómez A, Useros Fernández JL, Rodríguez Torres A 1991. Distribución por edad y sexo de las enfermedades de transmisión sexual en Valladolid. Estudio de 5.076 casos. Rev San Hig Púb. Madrid 65: 247-358.

Perea EJ, Alvarez-Dardet C, Borobio MV, Bedoya JM, Escudero J, Gallardo RM, González-Gabaldón B, Miguel C De, Moreno JC, Pérez-Bernal A, Rodríguez-Pichardo A 1981. Three years experience of sexually transmitted diseases in Sevilla, Spain. Brit J Vener Dis 57: 174-175.

Rein MF 1990. Clinical manifestations of urogenital trichomoniasis in women. In BM Honigberg, Trichomonads Parasitics in Humans, Springer Verlag, New York, p. 225-234.

Snipes LJ, Gamard PM, Narcisi EM, Beard CB, Lehmann T, Secor WE 2000. Molecular epidemiology of metronidazole resistance in a population of Trichomonas vaginalis clini- 
cal isolates. J Clin Microbiol 38: 3004-3009.

Sorvillo F, Kerndt P 1998. Trichomonas vaginalis and amplification of HIV-1 transmission. Lancet 351: 213-214.

Teras J, Roigas E 1966. Characteristics of the pathomorphological reaction in cases of experimental infection with Trichomonas vaginalis. Wiad Parazytol 12: 161-172.

Ulla M, Campos A, Baranda J, San Juan I, Villar V, Merino FJ, Larumbe ME, Gómez J 1993. Enfermedades de transmisión sexual en una subpoblación de alto riesgo de la provincia de Soria. Enferm Infecc Microbiol Clín 11: 299-303.
Viikki M, Pukkala E, Nieminen P, Hakama M 2000. Gynaecological infections as risk determinants of subsequent cervical neoplasia. Acta Oncol 39: 71-75.

WHO-World Health Organization 1997. An overwiew of selected curable sexually transmitted diseases In Global Program on AIDS, World Health Organization, Geneva, p. 227.

Zhang ZF, Begg CB 1994. Is Trichomonas vaginalis a cause of cervical neoplasia? Results from a combines analyses of 24 studies. Int J Epidemiol 23: 682-690. 